\title{
THE CONSEQUENCES OF CHILD SEXUAL ASSAULT
}

\author{
Arif Rohman \\ School of Humanities and Social Sciences, Charles Sturt University, \\ Locked Bag 678, Wagga Wagga, NSW, 2678, Australia \\ Email: arohman@csu.edu.au
}

\begin{abstract}
The understanding of the origin and nature of child sexual assault and its consequences is urgent. It benefits to child victims and helping institutions and the professionals who working in it. This article shows that child sexual assault basically was the product of patriarchal culture and sexist society which tend to marginalise the women and children's position, by creating some myths to legitimise male sexual violence. The occurrence of child sexual assaults has many consequences on children including physical and mental health. Another consequence is they may have to involve themselves in a prosecution process. Therefore, it is very important to understand the victim's problem. Understanding and giving sympathy to them during the making of reports to the police, during recovery from physical injuries and trauma, and during a prosecution process can help them to reach integration level and stability. The good coordination and collaboration between agencies and professionals can lead to the friendly services to the victims. Furthermore, children will not alone facing their problem during the recovery.
\end{abstract}

\section{A. Introduction}

Child sexual assault is one of the most important issues which are discussed not only in developing countries, but also in developed countries. The discussion of child sexual assault has entered the public spotlight due to the role of media in reporting it intensively. However, the media has to acknowledge the contribution of a coalition of the women's movement and the children's protection movement. This is because each of these groups has been successfully promoting the issue to social policy makers (Finkelhor, 1984: 3). The increasing number of child sexual assaults where females are the majority of victims, and the assumption that children are a vulnerable group who cannot protect themselves, becomes a basic argument and reason for their movements. This can be shown from the fact that $38 \%$ of girls less than 18 years old will be sexually assault in some way, while for the boys it is only $9 \%$. Thus, $76 \%$ of the girls know the perpetrators. Interestingly the offenders are often family members of their family, such as father, step father, mother's de facto partner, brother, uncle and grand father (CASA, 1990: 5).

Child sexual abuse could happen anywhere, both in urban areas and in rural areas, in the house, in the road, even in the school. It could be also carried out by anyone, such as parents and other family members, neighbours, friends or unknown people. 
Child sexual abuse also could happen at any time. Many researchers in their recent studies reveal that sexual assault will certainly bring some consequences to the victims and will greatly affect their lives. However, many people, mainly professionals, still have a lack understanding of this. As a result, the survivors did not receive the support and services which they need during the recovery process (Wilson, 1978: 110).

This article will examine child sexual assault and its consequences by using the feminism approach. It is my belief that children really suffer from sexual assaults because of the traumatic experiences which follow them. This will affect their physical and mental health in their future life. This suffering becomes worse when the helping institutions, such as police, hospital and courts fail to give much attention to the depth their problems, as they have been influenced by the patriarchal culture and the inequality of power between adults and children. In the beginning of this article I will provide a basic understanding of child sexual assault. After that I will explain the correlation between patriarchal culture and child sexual assault. Finally, I will discuss the reactions of victims after the incident, the effects of long-term trauma disorder, and offer some criticism of the helping institutions.

\section{B. Basic and Philosophical Concepts}

Feminists and child protectors believe that child sexual abuse has to be eliminated. However, they each have a different focus. The child protectors tend to view this phenomenon in the context of child abuse and neglect. As a consequence, they only see it as part of the family related sexual abuse when committed by parents and caretakers. They believe that child sexual abuse or incest can be the product of the family's pathology or of poor living conditions. Therefore all family members may have contributed to this pathology. By contrast, feminists see this problem as rape rather that child abuse. This is because they notice that child sexual abuse is not the matter of incest only, but it is larger than that. It could be done by a non-family member or a stranger. Feminists also argue that this phenomenon reflects gender inequality because of the fact that most victims are girls (Finkelhor, 1984: 4). Based on this evidence, the feminists prefer to look at this type of child sexual abuse as a rape rather than just child abuse, and to see it as an aggressive act or a crime rather than just the result of sexual desire.

However, some feminists today seem to avoid using the term rape and tend to use sexual assault for child sexual abuse. They think that 'sexual assault' is a more appropriate term because this connotation will help in positioning female into the centre stage, as victims. This explains why they struggle to vindicate the victim and suggest that rapists should be treated like murderers and executed, or sentenced to life imprisonment (Wilson, 1978: 1). 'Sexual assault' has a broader meaning rather than incest. This term refers to any sexual behaviour from offenders which make the victim feel uncomfortable, threatened or frightened. These include: touching, fondling or kissing; being made to look at, or pose for, pornographic photos; being masturbated or being forced to masturbate the offender; voyeurism; exhibitionism; 
verbal harassment/innuendo; oral/genital contact; and penetration of the victim's vagina, mouth and/or anus with a penis or object. Child sexual assault is criminal act for by an individual and by state law, whether by consent or non-consent, due to children's helplessness at this stage of their developmental. This definition contributes and helps victims to understand that other actions besides rape are criminal offences also (CASA, 1990: 4).

Feminists and child protectors agree to using the term of 'victim' or survivor for a child who has had sexual traumatic experience. In this context, a 'victim' refers to a child who has been sexually attacked by offenders. It is meant to diminish stigma and myths that blamed a child for inciting sexual assault. This is because the term victim refers to a powerless child due to the sexual assault, so that it is commonly used in the justice system. On the other hand, 'survivors' can be defined as children who have 'survived' from sexual assault acts due to their strength and their struggle. It is commonly used by professionals' assisting during the recovery process (Itzin, 2000: $3)$. Even though that victim is more powerless than the survivor, both victim and survivor can be used in a different context.

\section{The Root of Child Sexual Assault}

Even though child sexual assault can happen to boys, most cases are to girls. Feminists believe that child sexual assault is the product of the male dominant tradition which is long and deeply rooted in all aspects of living such as political, economic and social aspects (Ellis, 1989: 10). They argue that the phenomenon is basically due to the inequality of power distribution between men, women, and children. Simone de Beauvoir (1972: 77-78) said that sexuality plays a significant role in human life. Men who describe themselves as 'the-self' and women as 'others' feel threatened by women and the way for those men to feel secure is by oppressing women. They do this by creating a symbol and a myth so that women tend to become subordinate and institutionalised and see this as a destiny to which they are born (Connell, 2002: 30). According to Linda LeMoncheck (1985), women today live in man's world in which women are systematically sexualised by men in a way that dehumanises women. She believes that women are dehumanised in the domestic sphere, the economic and the political spheres and are taught to believe that men are always right and best.

Regarding the body image aspect as sexuality, Judith Butler (1993: 3) argues that perceptions of a woman's body are created, constructed and imposed through cultural norms. A woman has little choice relating to her body because the cultural norm governs her and her body. Butler mentions that this process, called 'performativity', is introduced and repeated until women accept and never question it. Butler also said that hegemonic culture can be shown by binary structures which appear in language and are accepted universally (Butler, 1990: 9).

Another feminist, Naomi Wolf (1990: 58) considers this situation by saying that the patriarchal culture has introduced the concept that 'men look at women and women 
watch themselves being looked at'. To explain this situation, probably we should look at what Mary Wollstonecraft said about woman. She argues that men always insult women with their rules. A woman should exhibit obedience and softness of temper. This attitude has been implanted since their infancy (Wollstonecraft, 1974: 23). Men can create the myth about their natural aggressiveness and masculinity so that they can keep hegemony and legalise their violence. The myths which were created by males to blame females in child sexual assault include: the victim deliberately asked to be raped; the victim could avoid the sexual assault if she does not walk alone at night; and incest happens due to the fault of a wife if she has ignored her sexual role. Based on this discussion, men have power so that they can objectify women as second class citizens designed for their pleasure. Therefore sexual violence can be understood as a product of a sexist society which has to pay for this 'dubious privilege' (Russel, 1984: 238).

Most sexual assaults to children are committed by adults. Child protectors believe that child sexual assault is the product of inequality of power between adults and children. This is shown by many cases of child sexual assault in which adults are often using the power to rape by trickery. This is related to the term of 'accessory-to-sex'. In this case, a victim agrees to co-operate because of her ignorance, inability and therefore does not know the implications of consent or non-consent. This may also be because of her personality or emotional development. The modus operandi that adults mostly use, is positioning their strength to control and to drive the victim into sexual relations (Briggs, 1993: 17). They often use money, sweets or toys, and offer emotional security to children who are their target of sexual assault (Davidson, 2008: 83).

In this unequality degree of power between children and adults, the child could not refuse to gratify the sexual desire of the adult. Herman (1981: 27) compared this situation with slavery in the past. The master could beat his slaves without reproach. He could sell their children, even have sexual relations with their wives. In the case of child sexual assault, children are the slaves, father as adult is the master.

In incest cases, the girl who has lived without a mother is naturally three times more vulnerable to sexual assault compared with other girls in general (Finkelhor, 1984: 26). This is because without her mother, the father can impose strong power and authority more easily thereby abusing his power. Furthermore, the feminists believe that the most dangerous combination of parents is when a girl's father is wealthy and educated while her mother is not. Here the role of the mother as the patron of the child often would not be powerful enough to protect her daughter. However, the poor and uneducated father also still has much power due to the patriarchal culture which gives greater power to men than women (Wood, 2007: 30). The adults have combined to create some myths which relate to child sexual assault, such as: incest rarely happens; the child's statement is a lie; and the rape has happened due to child's attractiveness (CASA, 1990: 17). 
Many studies reveal that a child learns that the relation between her mother and her father is often imbalanced. Father is identified as superior, dominant and powerful. As a consequence, this phenomenon could easily cause a child to imitate her mother's role and position and fall into a powerless situation of total dependence on her father. These studies also state that a wife who has had far less education than her husband was more likely to be trapped into lower bargaining power. Their children then learned the lesson that they must start to obey their father (Russel 1984: 261). This reflects the imbalance of power between children and adults and explains the root of sexual violence against children.

\section{Child Sexual Abuse and Its Impacts}

Their desire to understand the impact of child sexual assault causes many experts to refer to the physical and mental effects. The physical effects basically relate to the physical wounds of victims. These wounds are relative, depending on the level of violence that they received, considering their age and size. This wound could be a sore throat, while anal intercourse may cause rectal bleeding. Many cases also showed that child sexual assault can make the victims handicapped or cause death. They may also be vulnerable to infections, to sexually transmitted diseases, HIV/AIDS, and on pregnancy. The psychological effects usually refer to post-traumatic stress disorder (PTSD), cognitive distortion, depression, anxiety, antisocial behaviour, poor self-esteem, sexual dysfunction, even suicide (Briere \& Elliot, 1994: 55-61; Ligezinska, et. al., 1996: 112).

With regard to physical injury, Paul R. Wilson (1978: 49) explains that most victims experience a long-term physical effect. A 'long-term physical effect' refers to genitourinary disturbances and chronic rectal complaints. After having been attacked, victims try brushing various parts of their body including throat, thighs and breasts. They often have complaints such as headaches, sleep pattern disturbances, stomach pains, nausea, vaginal discharge, itching and the problems with urination. However, only a few victims see a doctor immediately after an attack. They prefer to cope by cleaning their body in the bathroom.

Emotional effects are very complex and usually refer to shame and guilty feelings. Burges and Holmstrom mention the rape trauma syndrome to explain how a victim often tends to overcome the situation after being attacked (Wilson, 1978: 49-50). This trauma syndrome manifests itself in such ways as changing their lifestyle, dreams and nightmare, and phobic reactions. They also felt so frightened of his family and loosing their friends. Dreams, nightmare and phobia usually happen frequently. They usually get up at midnight and scream. This dream and nightmare could happen even ten years after the attack. Feeling ashamed also occasionally made them lose self esteem and they felt self-degradation (Department of Health NSW, 1988: 4). They usually avoided men. Because of their problems they usually tend to leave their school. 
The impacts of child sexual assault can be understood from the victims' reactions stages. Dean \& deBruyn-Kops (1982: 110-113) divide the victim reactions into three phases. First, the phase I (Acute Reaction). This phase was marked by shock, mistrust, anger, confused, and fear. Many cases show that victims express their feelings by crying, being restless and tense. However some of them, in reverse, showed calm expression and try to conceal their feelings as if they have never been assaulted by adults. This phase usually is followed by physical complaints such as feeling tired, headache, nausea, or stomach-ache. For the girl experiencing vaginal intercourse, she usually had itchiness and pain around the vagina and problems in urination. Oral sex could cause sore throat while anal intercourse can cause rectal bleeding.

Victims are usually afraid to be alone and they have difficulty in sleeping. If they sleep they will often get up at midnight because of the nightmares. Their dream usually is about the violence that they have received and when they experience nightmares, they try to escape from the assaults. This problem usually leads to eating problems due to losing their appetite. Most victims also have a phobia about men and crowds of people. They very easily of wrongly associate a person with their offenders because of a small similarity. They often cry and suffer from depression. In some cases it leads to suicidal attempts (Williams \& Holmes, 1981: 103-105).

Second, the phase II (Outward Adjusment). In this stage, victims tried to start their new lives by doing some normal activities. They loose their desire to look for help and they do not want to discuss their bad experiences. Their physical health is getting better and their appetite is improved. Although they are still getting sleep disturbances and nightmares, the frequency is being reduced. Victims were also seen as hyperactive as they reorganised their lives, so they could attend their school (Wilson, 1978: 51). In this stage, the support from their families and the counsellors still is needed in order to get their confidence to start a new life.

Lastly, the phase III (Integration). In this stage, victims possibly withdraw from their social life and avoid contact with people. They fight to understand their trauma experience. They also possibly refuse support and help from people. For some girls this is a long period of adjustment. The sexual trauma is difficult to forget but with the support and help of counsellors, families and their friends, they will think positively and begin to fill their life with something productive (Dean \& deBruynKops, 1982: 113). In some cases, even though they have reached integration or acceptance by the passing of time, they sometimes will revert back to the first and second phases. Based on these facts, it could be understood that the reaction stages for victims run in spirals rather than in linear processes.

Finkelhor \& Browne (1985: 530) put forward the concept of traumagenic dynamics to analyse the traumatic impacts of child sexual abuse, which covered traumatic sexualisation, betrayal, powerlessness and stigmatisation. Traumatic sexualisation refers to a process where after the incident, the child suffers interpersonality dysfunction and develops unusual sexual behaviour. Because of carrying out sexual 
relations in the period of pre-puberty, this experience will be retained vividly in their memory. Because they are still under supervision, they afterwards experience confusion and misconception and finally tend to carry out unusual social activity.

They are hurt when they discover betrayal from those they trust and depend on. The child begins to realise that the person whom they trusted and loved deeply told lies and disregarded them; and of course afterwards they felt they could not believe in them ever again, blamed them and did not want to meet them (Finkelhor \& Browne, 1985: 531). Powerlessness or perhaps disempowerment can occur when the girl feels she was not powerful enough because her territory and body space was violated by others using violence and manipulation. Because of their powerlessness girls often experience 'revictimisation'. This process is marked by a decline in coping skills, casualties and low selfesteem. Casualties usually experience despair, depression, and even suicidal behaviour (CMC, 2007: 8).

Stigmatisation referred in the last process is where the children felt embarrassed and guilty because of being stamped as negative in their environment. They felt they were pressed whenever hearing the gossip from the family, the friend and community about their behaviour that was considered deviant and taboo. The community also afterwards gave the stigma of 'loose morals' or 'spoiled goods' (Fontes, 2005: 145-149). The effect could, from this process, leave them developing the selfdestructive behaviour, and in danger of drug or alcohol abuse, criminal activity and prostitution (Arnow, et. al., 1999: 762).

\section{E. Helping Institutions and Criticism}

It is surprising that many cases of child sexual assault have been not reported to the police. Some experts estimate that only 1 out of 10 victims of child sexual abuse reported their case to the police (NACA, 1989: 5). This makes it difficult for policy makers to know what the real number of the cases is. It seems that the number of cases today is like the tip of an iceberg where the actual number probably is much higher. Dean \& deBruyn-Kops (1982: 63) say that the fear factor due to the treatment of the police and the procedure of the case has affected victims so much that they do not report their cases to the police. They give an example of how a victim has been investigated by five uniformed policemen. Sometimes the police have called in the middle of the night just asking for clarity. The other reason was mentioned by Wilson (1978: 70), that many police often suspected victims and were hostile and unsympathetic to them.

The other reason why victims did not want to report their cases is because the perpetrators often threaten them if they report to the police, they will come back and hurt them. Even though the threats are not real, it really affects victims. Many victims felt that the sexual assault at that time was enough and they did not want to look for more trouble. Victims also often felt that reporting to the police is a waste of time. This is because in many cases the perpetrators cover their face and disappear in 
the dark (Wilson, 1978: 59),. By reporting the case to the police it was like repeating the sexual experience; a memory which is very painful for them.

In the case where the perpetrators are family's members, reporting their case only makes their relations to other family's members become worse. Moreover, if the perpetrator was a father of the victim and he is the only man who supports financially the family, reporting and sending him to the jail is a difficult choice. As a consequence, he cannot support his family again and all family members will suffer (Schwendinger \& Schwendinger, 1983: 42). This is also influenced by media reporting. The intensity of media in reporting the case only makes victims more ashamed. Many victims also mention that reporting means opening the case again. As a result, many people will know what happened and the victims are seen as stereotypes and as dirty people. Furthermore, when perpetrators are fathers, often their mothers and brothers do not believe them, and call them liars.

Two important issues related to the hospital services are the risk of pregnancy and affected venereal disease. Medical professionals in the hospital can give diethylstilbestrol to prevent pregnancy. However, this pill is not effective after 72 hours from the incident. Other treatment to prevent pregnancy is by using postcoital IUD and menstrual extraction. The workers have to give information for the importance tests, and the medical treatment to venereal disease. Tests for such as gonorrhoea, syphilis and the HIV/AIDS are very important to know about exactly to reduce the risks (Dean \& deBruyn-Kops, 1982: 77-78). At the same time, counselling is needed to help victims reduce their fears and doubts. A social worker could also help victims in preparing preoperation and could help them to socialise with their family and community.

However, the hospital was often the weakest agency in helping to provide proof in the case of child sexual assault. This is because many doctors and the agency are worried about being involved in a trial process that often takes much time. They sometime avoided doing proof rechecks that would be showed by defence attorneys. The hospital that received the victim also usually isolated them in the emergency room and treated them differently from ordinary patients and this made victims feel very uncomfortable. This is possibly because the professionals are not trained in the special case of child sexual assault (Dean \& deBruyn-Kops, 1982: 74). Other criticism of the hospital services is that in many cases boys have received better treatment than girls (Spataro, et. al., 2004: 416). The expensive cost of treatment during recovery also becomes a barrier for the victims for accessing hospitals.

The interesting thing in the case of child sexual abuse is that many offenders have not been sentenced by the law. Many reasons were used to explain why perpetrators can go free. This is because the trial process often took a very long time. The process in the court often made victims experience a 'second rape' as many people in the court doubt their testimony as they are still children (Kendall-Tackett, et.al., 1993: 172; Sanders, 1980: 110). Media publication also made children feeling ashamed and 
tended to stop the prosecution process. In some cases the practice of 'bargaining for peace' between the victim's family and the perpetrators is a major issue in the prosecution process. In the case of incest, children tended to avoid statements which opposed their parents or their caretaker (Davidson, 2008: 50). Other criticism is that perpetrators usually use mental disturbance as a reason, so that they can escape from the law.

Regarding this, in Indonesia, people often try to solve these cases outside the prosecution process. Ironically, most of practices are mediated by the police or attorneys. For example, in Aceh there is a ritual called 'paseujeuk' as part of the tradition, where victims' family and perpetrators will meet. The perpetrators then give an amount of money as compensation. It is also common that the perpetrators' statement that they will take responsibility and marry the victims have been considered as good will and a problem solution, although the perpetrators have many wives already.

\section{F. Toward A Friendly and A Better Services}

The management and treatment from helping institutions and the professionals are the important factor in child sexual assault. This can be seen as a serious challenge and is because of the complexity of the problem itself. Child sexual assault cases are very complicated because it concerns many institutions such as medical institutions, child protection institutions, and law institutions (police and attorney). It is difficult to decide the territory of each. This overlap sometimes makes the case a puzzle and makes the victim confused. It seems that there is no coordination between these institutions. Participation from community agencies with no experience in collaborating with other agencies and no clear division between their institutions makes the case management extremely difficult (Finkelhor: 200-201).

In this case, professionals need to understand the philosophy of each institution. For example, child protection agencies see the problem from family dysfunction, so that they insist on focusing the family system for their service. By contrast the mental health workers see it as the case of psychological problem so that providing counselling is the best choice for intervention. This explains why during case conferences a high disagreement often occurs, as to which course to take. This phenomenon also happens between workers in the same institutions. However, the differences should be eliminated by combining their power and resources, and working together. This coordination can be started by one institution such as state child protective service. If not then the victims will become frustrated and the professionals will never work together. This is a must for the best interest of the child.

\section{G. Conclusion}


This article has shown that child sexual assault basically was the product of patriarchal culture and sexist society which tend to marginalise the women and children's position, by creating some myths to legitimise male sexual violence. The occurrence of child sexual assaults has many consequences on children including physical and mental health. Another consequence is they may have to involve themselves in a prosecution process. Therefore, it is very important to understand the victim's problem. Understanding and giving sympathy to them during the making of reports to the police, during recovery from physical injuries and trauma, and during a prosecution process can help them to reach integration level and stability. The professionals also need to collaborate with other agencies with good coordination in the best interests of the child. Finally, friendly and non gender-biased media, family, and the community also can support them to get self confidence faster, and enable them to master the traumas and dysfunctions caused by the assault.

\section{Selected Bibliographies:}

Arnow, B.A. et.al. 1998, 'Childhood Sexual Abuse, Psychological Distres, and Medical Use Among Women', Psychosomatic Medicine, vol. 61, pp. 762-770.

Beauvoir, S.d. 1989, The Second Sex, New York, Vintage Books.

Briggs, F. 1993, Why My Child?, St. Leonards NSW, Allen \& Unwin.

Briere, J.N. \& Elliot, D.M. 1994, 'Immediate and Long-Term Impacts of Child Sexual Abuse', The Future of Children, vol. 4, no. 2, Summer/Fall, pp. 54-69.

Butler, J. 1993, Bodies That Matter, New York, Routledge.

------. 1990, Gender Trouble, New York, Routledge.

CASA (The Centre Against Sexual Assault) The Royal Women's Hospital. 1990, Breaking the Silence: A Guide to Supporting Victims/Survivors of Sexual Assault, Melbourne, CASA House.

CMC (Crime and Misconduct Commission). 2007, Breaking the Cycle: A Study of Victimisation and Violence in the Lives of Non-Custodial Offenders, Queensland, CMC.

Connell, R.. 2002, 'Differences and Bodies', in Gender, Blackwell, Polity, Cambridge, pp. 28-52.

Davidson, J.C. 2008, Child Sexual Abuse: Media Representations and Government Reactions, New York, Routledge-Cavendish.

Dean, C.W. \& deBruyn-Kops, M. 1982, The Crime and the Consequencesof Rape, Illinoois, Charles C Thomas.

Department of Health, NSW. 1988, Sexual Assault Services: Policy and Procedure Manual, Sydney, State Health Publication.

Ellis, L. 1989, Theories of Rape: Inquiries into the Causes of Sexual Aggression, New York, Hemisphere.

Finkelhor, D. \& Browne, A. 1985, 'The Traumatic Impact of Child Sexual Abuse: A Conceptualisation', American Journal of Orthopsychiatry, vol. 55, no. 4, pp. 530-541.

Finkelhor, D. 1984, Child Sexual Abuse, New York, The Free Press.

Fontes, L.A. 2008, Child Abuse and Culture, London, The Guilford Press.

Herman, J. 1981, Father-Daughter Incest, Cambridge: Harvard University Press.

Itzin, C. 2000, 'Child Sexual Abuse and the Radical Feminist Endeavour', in Home Truths About

Child Sexual Abuse: Influencing Policy and Practice, London, Routledge, pp. 1-24. 
LeMoncheck, L. 1985, Dehumanizing Women, New Jersey, Rowman \& Allanheld.

Ligezinska, M. et. al. 1996, 'Children's Emotional and Behavioral Reactions Following the Disclosure of Extrafamilial Sexual Abuse: Initial Effects', Child Abuse and Neglect, vol. 20, no. 2, pp. 111-125.

Russell, D.E.H. 1984, Sexual Exploitation: Rape, Child Sexual Abuse and Workplace Harassment, London, Sage Publications.

Sanders, W.B. 1980, Rape and Woman's Identity, London, Sage Publications.

Spataro, J. et. al. 2004, 'Impact of Child Sexual Abuse on Mental Health: Prospective Study in Males and Females', British Journal of Psychiatry, vol. 184, pp. 416-421.

Williams, J.E. \& Holmes, K.A. 1981, The Second Assault: Rape and Public Attitudes, London, Greenwood Press.

Wilson, P.R. 1978, The Other Side of Rape, Brisbane, University of Queensland Press.

Wolf, N. 1990, The Beauty Myth, London, Vintage.

Wollstonecraft, M. 1974, The Rights of Woman, New York, J.M. Dent \& Sons Ltd.

Wood, J.T. 2007, Communication, Gender, and Culture: Gendered Lives, 7th edn. Belmont, Thomson Wadsworth. 